\title{
SOLUCIÓN DE CONTROVERSIAS EN LOS TRATADOS BILATERALES DE INVERSIÓN: MAPA DE SITUACIÓN EN AMÉRICA DEL SUR
}

\section{SOLUCÃO DE CONTROVÉRSIAS NOS TRATADOS BILATERAIS DE INVESTIMENTO: MAPA DE SITUAÇẪO NA AMÉRICA DO SUL}

Magdalena Bas Vilizzio*

Resumen: Este trabajo analiza las características particulares del sistema legal internacional de solución de controversias inversor-Estado, con especial foco en los tratados bilaterales de inversión (TBI) en vigor en América del Sur, salvo excepciones. En este marco, aplicando la teoría de los regímenes internacionales (Krasner, 1983), se examinan las tres posiciones de los Estados de la región en torno al tema: 1) no ratificar TBI ni ser miembro del Centro Internacional de Arreglo de Diferencias relativas a Inversiones (CIADI) (Brasil); 2) denunciar los TBI en vigor y abandonar el CIADI (Bolivia, Ecuador y Venezuela); 3) mantener los TBI en vigor $y$ permanecer en los foros de solución de controversias actuales (Argentina, Chile, Colombia, Guyana, Paraguay, Perú, Surinam y Uruguay).

Resumo: Este trabalho analisa a características particulares do sistema legal internacional da solução de controvérsias em matéria de investimentos, com especial foco nos tratados bilaterais de investimento (TBI) em vigor na América do Sul, salvo excepções. Neste marco, aplicando a teoría dos regímenes internacionais (Krasner, 1983), se examinam as três posições dos Estados da região em torno do tema: 1) não ratificar TBI nem ser membro do Centro Internacional de Solução de Controvérsias Relativas a Investimento (ICSID) (Brasil); 2) denunciar os TBI em vigor e sair do ICSID (Bolívia, Equador e Venezuela); 3) manter os TBI em vigor

\footnotetext{
* Profesora Adscripta de Derecho Internacional Público de la Universidad de la República. Profesora de Derecho del Comercio Internacional de la Universidad de Montevideo, Uruguay. E-mail: magdalenabas@gmail.com

Este trabajo se enmarca en la investigación titulada "América del Sur frente a los tratados bilaterales de inversión: ¿hacia un retorno del Estado en la solución de controversias?", que es desarrollada por la autora con financiación de la Comisión Sectorial de Investigación Científica de la Universidad de la República (Uruguay), sin abarcarla en su totalidad. La autora agradece especialmente los valiosos aportes realizados por la profesora Ana Pastorino y los entrevistados.
} 
e ficar nos fóruns de solução de controvérsias atuais (Argentina, Chile, Colômbia, Guiana, Paraguai, Peru, Suriname e Uruguai).

Palabras clave: Solución de controversias, Tratados bilaterales de inversión, Centro Internacional de Arreglo de Diferencias relativas a Inversiones (CIADI), América del Sur

Palavras-chave: Solução de controvérsias, Tratados bilaterais de investimento, Centro Internacional de Solução de Controvérsias Relativas a Investimento (ICSID), América do Sul

\section{INTRODUCCIÓN}

En sus relaciones externas, los Estados independientes requieren un marco regulatorio que contribuya a preservar su soberanía, atributo jurídico que los Estados independientes se conceden y se reconocen recíprocamente y en forma excluyente de cualquier otro tipo de organización. Surge así, la necesidad de un sistema jurídico de coordinación como el Derecho Internacional Público. Sin embargo, la regulación de ciertos temas ha generado cambios que cuestionan algunos postulados tradicionales del sistema legal internacional general o Derecho Internacional Público. Tal es el caso del sistema legal internacional de solución de controversias inversor-Estado, basado principalmente en los TBI y el Convenio de Washington sobre arreglo de diferencias relativas a inversiones entre Estados y nacionales de otros Estados (CW) que crea el CIADI.

En este marco, el presente trabajo procura aportar al debate sobre los mecanismos de solución de controversias previstos en los TBI de Estados Sudamericanos ${ }^{1}$ que se encuentran en vigor, salvo excepciones. Asimismo, en el entendido que el sistema legal internacional de solución de controversias inversor-Estado es un régimen internacional de Krasner (1983), se analizan las tres posiciones de los Estados Sudamericanos en torno al tema: no ser parte del régimen (Brasil), abandonarlo (Bolivia, Ecuador y Venezuela) y permanecer en él (Argentina, Chile, Colombia, Guyana, Paraguay, Perú, Surinam y Uruguay).

\section{SOLUCIÓN DE CONTROVERSIAS EN LOS TRATADOS BILATERALES DE INVERSIÓN: ¿CAMBIOS AL SISTEMA LEGAL INTERNACIONAL GENERAL?}

Los mecanismos de solución de diferencias previstos por TBI, generalmente remiten al arbitraje internacional en el cual los inversores

1 Este trabajo no tiene en cuenta los capítulos de inversiones previstos en tratados de libre comercio $\mathrm{u}$ otros instrumentos internacionales multilaterales. 
extranjeros tienen locus standi para demandar a los Estados en caso de incumplimiento. Tal es el caso de los tribunales arbitrales ad hoc del CIADI, organización internacional que forma parte del Grupo Banco Mundial ${ }^{2}$, la Corte Permanente de Arbitraje, la Cámara de Comercio Internacional, la Cámara de Comercio de Estocolmo, Corte Internacional de Arbitraje de Londres, u otras instancias de arbitraje ad-hoc ${ }^{3}$. Esta situación evidencia un cambio o excepción al sistema clásico de la protección diplomática, según el cual es el Estado de la nacionalidad del particular afectado quien hace propio el reclamo frente al Estado incumplidor ${ }^{4}$ y no el particular ${ }^{5}$ (Torreja Mateu, 2012, 317; Burgos-De la Ossa y Lozada-Pimiento, 2009: 272).

Asimismo, los TBI presentan otro cambio o excepción al sistema clásico dado que en numerosos acuerdos no se condiciona el proceso arbitral internacional al previo agotamiento de los recursos internos en el Estado demandado, como propone la doctrina Calvo ${ }^{6}$ (Herz, 2003: 13, Fernández Alonso, 2013: 46) (ver gráfica 17). Esta doctrina, elaborada en 1968 por el jurista argentino Carlos Calvo y recogida en varias constituciones latinoamericanas, se basa en los principios de igualdad soberana, no intervención y trato igualitario entre extranjeros y nacionales. Los Estados, como soberanos, tienen derecho determinar libremente sus políticas internas y externas, sin injerencia extranjera, y dado que los extranjeros tienen iguales derechos a los nacionales, estos deben agotar todos los recursos de la jurisdicción doméstica sin pedir la protección y/o intervención diplomática de su Estado de su nacionalidad (Tamburini, 2002: 82).

Basados en la doctrina Calvo, en la reunión anual de la Junta de

2 Son parte del Grupo Banco Mundial el Banco Internacional de Reconstrucción y Fomento, la Asociación Internacional de Fomento, Corporación Financiera Internacional, el Organismo Multilateral de Garantía de Inversiones y el CIADI.

3 Por ejemplo bajo el Reglamento de arbitraje de la Comisión de las Naciones Unidas para el Derecho Mercantil Internacional (UNCITRAL).

4 En el régimen general de protección diplomática, la doctrina mayoritaria y el Proyecto de artículos sobre protección diplomática de la Comisión de Derecho Internacional de la Organización de Naciones Unidas, 2006, condiciona el ejercicio de la misma a que el particular afectado tenga un vínculo de nacionalidad con el Estado reclamante, y que agote previamente de los recursos internos en el Estado incumplidor. Una parte minoritaria de la doctrina exige adicionalmente que el particular no haya contribuido con su conducta al hecho que le ha causado el daño (Torroja Mateu, 2012: 322).

5 La protección diplomática es un derecho del Estado que la ejerce y las normas que la regulan son dispositivas, de allí la posibilidad de excepción total o aplicación parcial.

6 Fach Gómez señala que varios TBI presentan una versión "light” de la cláusula Calvo, al permitir pasar al arbitraje internacional una vez sometida la controversia a la jurisdicción doméstica, se puede pasar al arbitraje por vencimiento de plazo de tiempo determinado (Fach Gómez, 2010: 3).

7 La gráfica 1 muestra que de los 275 TBI de Estados Sudamericanos analizados en este trabajo, únicamente en 33 de ellos está presente la obligación de previo agotamiento de los recursos interno. Ambas cifras comprenden la duplicación de acuerdos entre Estados. Por ejemplo, el TBI entre Argentina y Bolivia es incluido tanto en las cifras correspondientes a Argentina como Bolivia. Excluyendo la duplicación, serían 32 de 255 acuerdos. 
Gobernadores del Banco Mundial en setiembre de 1964 en Tokio, una serie de Estados Latinoamericanos ${ }^{8}$ junto a Irak y Filipinas votaron en contra del borrador preliminar del CW, cuyo texto final es aprobado 1965 y entra en vigor en 1966. Este hecho se conoce como el "no de Tokio" (Schreuer, 2009: 2 - 3; Fach Gómez, 2010: 2; Boeglin, 2012). Años después el "no" se revertiría (ver punto 3.1).

Gráfica 1: TBI en Sudamérica que incluyen la obligación de previo agotamiento de los recursos internos. Comparación por Estado.

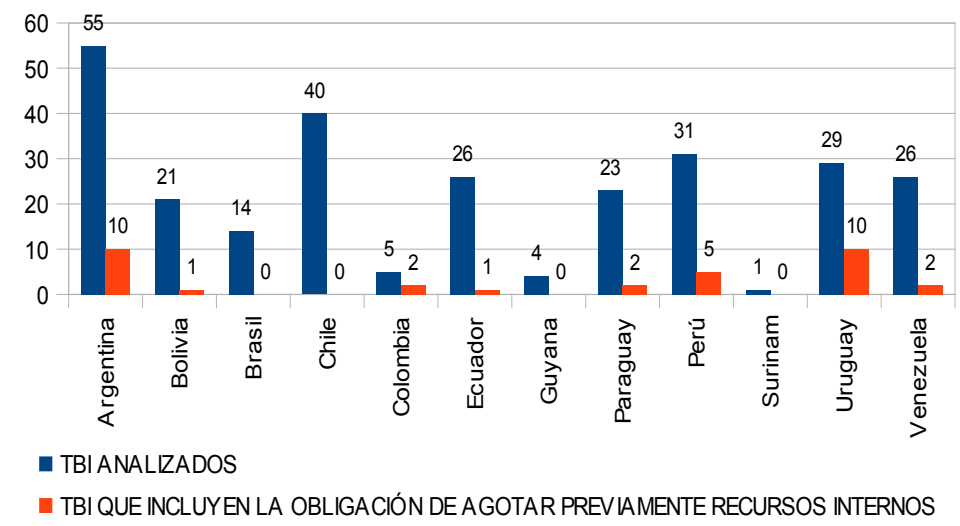

Fuente: Elaboración propia en base a datos de la UNCTAD y Cancillerías de los Estados. Actualizado al 31 de enero de 2015.

Nota: Para la elaboración de la gráfica se toman los TBI en vigor, salvo las excepciones de Brasil, Bolivia, Ecuador y Venezuela. En el caso de Brasil se incluyen los acuerdos firmados y no aprobados por el Congreso. Se toman los TBI en vigor al inicio del proceso de denuncia en Bolivia, Ecuador y Venezuela, en cada uno y en los demás Estados.

En aquellos TBI que se prevé obligatoriamente el agotamiento previo de los recursos domésticos, no obstante, por el juego de la cláusula de la nación más favorecida (CNMF) contenida en la casi totalidad de los TBI celebrados en el mundo, puede eludirse dicha obligación ${ }^{9}$. Esta práctica se funda en el acceso al mejor trato que un Estado decide ofrecer a los inversores en el marco de otro acuerdo, en este caso, pasaje

8 Los Estados Latinoamericanos son Argentina, Bolivia, Brasil, Chile, Colombia, Costa Rica, República Dominicana, Ecuador, El Salvador, Guatemala, Haití, Honduras, México, Nicaragua, Panamá, Paraguay, Perú, Uruguay y Venezuela (Boeglin, 2012). Al 31 de enero de 2015, todos los Estados del "no de Tokio" son parte del CW, salvo Brasil, México e Irak que nunca adhirieron, República Dominicana que adhirió pero no lo ratificó, y Bolivia, Ecuador y Venezuela que lo denunciaron (ver apartado 4.2).

9 A esta práctica se le denomina treaty shopping o cherry picking. 
directo a la jurisdicción arbitral internacional. De acuerdo a Banifatemi, "un Estado tiene la libertad innegable de no ofrecer un mejor trato a otros inversores o no incluir una CNMF. Sin embargo, una vez que libremente ha elegido uno de esos caminos, debe atenerse a aquello que se ha obligado." (Banifatemi, 2009: 273).

En el caso Emilio Agustín Maffezini contra España (CIADI caso número $\mathrm{ARB} / 97 / 7)$, por primera vez un tribunal arbitral aplica la CNMF a los mecanismos de solución de controversias. En este caso, el demandante somete la controversia en base al TBI entre Argentina y España cuyo artículo X numeral 3 establece que se puede pasar al arbitraje internacional: a) si en un plazo de dieciocho meses no hay sentencia en la jurisdicción doméstica; b) cuando haya decisión pero subsista la controversia; o, c) por acuerdo de partes. En función de la CNMF del TBI en cuestión, el demandante solicita la aplicación de las disposiciones más favorables del TBI entre España y Chile. En el último acuerdo, luego de procurar obtener una solución amigable en un plazo de seis meses, la jurisdicción doméstica se presenta como una opción para el inversor, junto a la jurisdicción arbitral internacional: CIADI, mecanismo complementario del CIADI, tribunal arbitral ad-hoc según el Reglamento de Arbitraje de la UNCITRAL (artículo 10).

Por tanto, en la decisión sobre jurisdicción de fecha 25 de enero de $2000^{10}$, el tribunal considera que,

si un tratado con un tercero contiene disposiciones para la solución de controversias que sean más favorables para la protección de los derechos e intereses del inversor que aquellos del tratado básico, tales disposiciones pueden extenderse al beneficiario de la cláusula de la nación más favorecida pues son plenamente compatibles con el principio ejusdem generis. Naturalmente que el tratado con el tercero tiene que referirse a la misma materia del tratado básico, sea ésta la protección de inversiones extranjeras o la promoción del comercio, puesto que las disposiciones sobre solución de controversias se aplicarán en el contexto de estas materias; de otro modo se incurriría en contravención de dicho principio (párrafo 54) ${ }^{11}$.

En la acera contraria se encuentra el caso Plama Consortium contra Bulgaria (CIADI caso número ARB/03/24), en el cual el tribunal

10 Texto disponible en el sitio web del CIADI: <https://icsid.worldbank.org/>.

11 Con este precedente, en oportunidades posteriores, otros tribunales arbitrales del CIADI hacen lugar a la CNMF en relación a los mecanismos de solución de controversias, como ser: Gas Natural SDG SA Contra Argentina (CIADI caso número ARB/03/10); Suez, Sociedad General de Aguas de Barcelona SA e InterAguas Servicios Integrales del Agua SA contra Argentina (CIADI caso número ARB/03/17); National Grid PLC contra Argentina (caso bajo el Reglamento de Arbitraje de la UNCITRAL); Suez, Sociedad General de Aguas de Barcelona S.A. Y Vivendi SA contra Argentina (CIADI caso número ARB/03/19). 
arbitral entiende que la CNMF es aplicable únicamente a las cuestiones de fondo relativas a los mecanismos de solución de controversias, no así a las procesales. Siguiendo esta línea de interpretación restringida de la CNMF, en el caso Telenor Mobile Communications AS contra Hungría (CIADI caso número ARB/04/15), el tribunal arbitral reconoce la importancia de tener en cuenta las intenciones de las partes en el TBI de incluir o excluir el trato de nación más favorecida a determinadas cuestiones, esto es, la interpretación de la cláusula debe ser acorde a las limitaciones previstas en el propio acuerdo.

\section{EVOLUCIÓN DE LOS TRATADOS BILATERALES DE INVERSIÓN EN SUDAMÉRICA}

\subsection{La década del noventa: clima propicio para los tratados bilaterales de inversión y el Convenio de Washington}

En Sudamérica, la década del noventa representa el momento de mayor auge de firma y ratificación de TBI y adhesión al $\mathrm{CW}^{12}$, aun en Estados tradicionalmente partidarios de la doctrina Calvo (Costa, 2008: 127). Una serie de factores generaron un clima propicio, comenzando por las reformas estructurales promovidas por las organizaciones económicas internacionales en el marco del llamado consenso de Washington, que, entre otros puntos, propulsaron la desregulación del mercado, la apertura comercial mediante la rebaja de aranceles y eliminación de barreras no arancelarias, la privatización de servicios públicos y la liberalización de las barreas a la inversión extranjera directa (IED) (Fernández Alonso, 2013: 48 - 50; Bohoslavsky, 2010: 18). En este marco, los TBI tienen como objetivo compensar los riesgos políticos o no comerciales, especialmente en países en desarrollo, evitando cualquier cambio en la legislación nacional que sea factible de afectar tales inversiones y generando un clima de seguridad política para el inversor (De Azevedo, 2001: 4).

Por otra parte, el fracaso en la concreción del Acuerdo Multilateral de Inversión impulsado por la Organización para la Cooperación y el Desarrollo en $1995^{13}$, deriva en una mayor proliferación de TBI. Como muestra la gráfica 2, de los 275 acuerdos analizados, 226 fueron

\footnotetext{
12 Al 31 de enero de 2015, han ratificado el CW los siguientes Estados Sudamericanos: Argentina (desde el 18 de noviembre de 1994), Chile (desde el 24 de octubre de 1993), Colombia (desde el 14 de agosto de 1997), Guyana (desde el 10 de agosto de 1963), Paraguay (desde el 6 de febrero de 1983), Perú (desde el 8 de setiembre de 1993) y Uruguay (desde el 8 de setiembre de 2000). El convenio fue denunciado por Bolivia (denuncia notificada el 1 de mayo de 2007), Ecuador (denuncia notificada el 2 de julio de 2009) y Venezuela (denuncia notificada el 24 de enero de 2012), en todos los casos efectivas seis meses después según el artículo 71 del convenio. Finalmente, Brasil y Surinam nunca adhirieron al mencionado tratado.

13 Este acuerdo pretendía vincular incluso a países no miembros de la organización.
} 
firmados en la década de los $90^{14}$. Se destaca particularmente el caso de Argentina, Estado con mayor número de TBI en la región.

Gráfica 2: TBI en Sudamérica firmados en la década de los 90. Comparación por Estado.

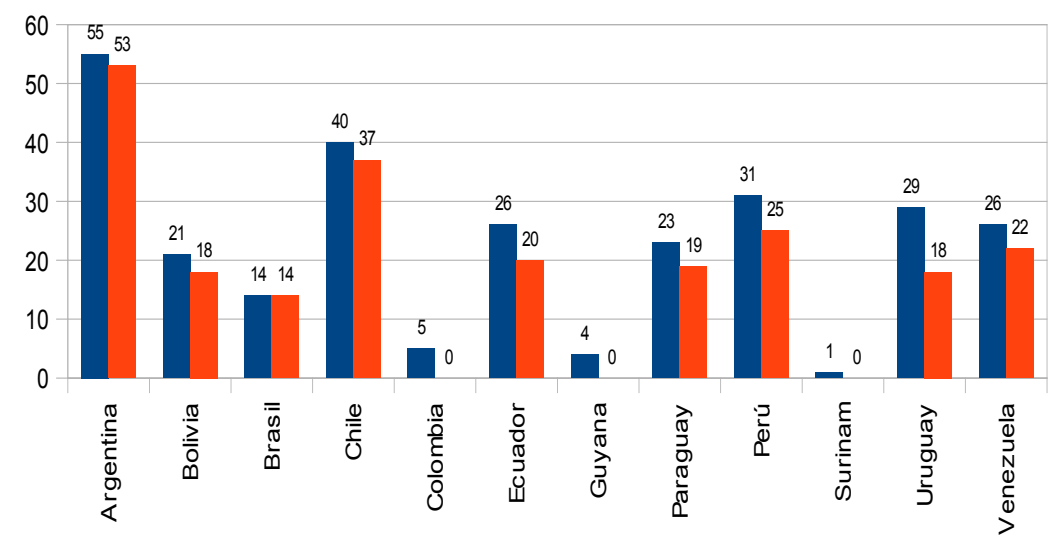

- TBIANALIZADOS - TBIFIRMADOS EN LA DECADA DELOS 90

Fuente: Elaboración propia en base a datos de la UNCTAD y Cancillerías de los Estados. Actualizado al 31 de enero de 2015.

Nota: Ídem gráfica 1.

Los TBI firmados siguen los estándares generales, conteniendo disposiciones que regulan diversas áreas que pueden agruparse en: 1) Normas generales de trato de la inversión: alcance y definición de inversión, trato nacional, CNMF, trato justo y equitativo; 2) Protección de las inversiones: garantías y compensaciones por expropiación, garantías de libre traspaso de fondos y transferencia de capitales y ganancias al exterior, prohibición o límites a los requisitos de desempeño; 3) Excepciones, modificaciones y terminación del tratado; 4) Solución de controversias: mecanismos de solución de controversias Estado-Estado e inversor-Estado (Carrau y Valdomir, 2012: 49; Salacuse: 2010: 127 128). En cuanto al último punto, los TBI de Estados Sudamericanos presentan como mecanismos de solución de controversias más habituales el arbitraje en el CIADI (89\%), jurisdicción doméstica del Estado receptor (71\%), tribunal ad hoc según Reglamento de Arbitraje de la UNCITRAL (63\%), el mecanismo complementario del CIADI (39\%) y arbitraje ad hoc (12\%) (ver gráfica 3).

14 Ambas cifras comprenden la duplicación de acuerdos entre Estados. Excluyendo la duplicación, serían 207 de 255 acuerdos. 
Gráfica 3: Mecanismos de solución de controversias previstos en TBI en Sudamérica

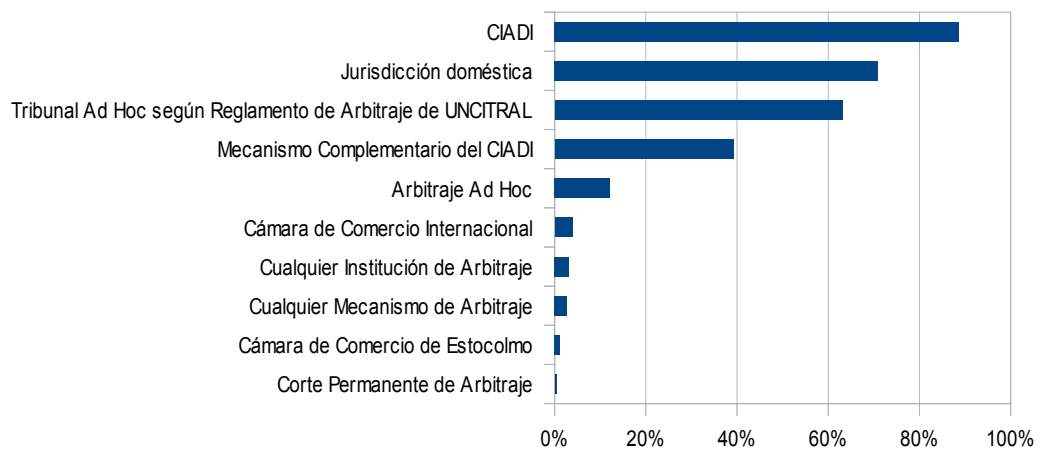

Fuente: Elaboración propia en base al texto de los acuerdos. Actualizado al 31 de enero de 2015.

Cabe destacar que el CIADI no es un tribunal internacional permanente, sino una organización que maneja una lista de árbitros y para cada caso concreto se compone un tribunal con la elección de un árbitro por cada una de las partes y otro por el Centro. Para que el CIADI entienda en una controversia inversor-Estado es necesario que la controversia sea de naturaliza jurídica, tenga una relación directa con una inversión entre un Estado parte y un nacional de otro Estado parte, y haber firmado una cláusula de prórroga de jurisdicción por escrito (artículo 25 del CW) ${ }^{15}$. Por tanto, "fueron los TBI los instrumentos idóneos para que este consentimiento quedara manifestado, en tanto la mayoría de ellos incluye el arbitraje ante el CIADI como mecanismos para la resolución de disputas." (Costante, 2012: 77).

Sin embargo, siguiendo la tendencia internacional, la década del noventa no fue foco de un gran número de demandas contra los Estados Sudamericanos ${ }^{16}$. Tomando el caso del CIADI, totalizaron nueve demandas,

15 El Reglamento del mecanismo complementario para la administración de procedimientos por el Secretariado del CIADI, prevé la posibilidad que el Centro administre procedimientos fuera del ámbito de aplicación del CW. Esto es: 1) conciliación o arbitraje para la solución de controversias de carácter jurídico que surjan directamente de una inversión entre un Estado y un nacional de Estados que no sean parte del CW; 2) conciliación y arbitraje que no surjan directamente de una inversión, siempre que el Estado o el nacional sean parte del CW; 3) procedimientos de comprobación de hechos (artículo 2). La posibilidad 1 es la que permite la presentación de cinco casos de arbitraje contra Venezuela por parte de empresas canadienses previamente a que Canadá sea parte del CW (1 de diciembre de 2013). Esto son: Vannessa Ventures Ltd contra Venezuela (CIADI caso número ARB(AF)/04/6); Gold Reserve Inc contra Venezuela (CIADI caso número ARB(AF)/09/1); Nova Scotia Power Incorporated contra Venezuela (CIADI caso número ARB(AF)/11/1); Crystallex International Corporation contra Venezuela (CIADI caso número $\mathrm{ARB}(\mathrm{AF}) / 11 / 2)$; y Rusoro Mining Ltd contra Venezuela (CIADI caso número ARB(AF)/12/5).

16 Los Estados demandados fueron Argentina (cinco demandas), Chile (1 demanda), Paraguay, (1 demanda), Perú (1 demanda) y Venezuela (1 demanda). 
habiéndose registrado la primera el 26 de junio de 1996 por parte de la empresa Fedax NV contra Venezuela (CIADI caso número ARB/96/3), en base al TBI entre Venezuela y Países Bajos. La segunda demanda se presenta el 17 de febrero de 1997, Compañía de Aguas del Aconquija S.A. y Vivendi Universal SA contra Argentina (CIADI caso número ARB/97/3), invocando el TBI entre Argentina y Francia. En la gráfica 4 puede apreciarse la tendencia al aumento en el número de casos registrados a partir de la década del 2000, tanto para Sudamérica como los demás miembros de la organización.

Gráfica 4: Casos de arbitraje registrados por el CIADI por año, según demandado.

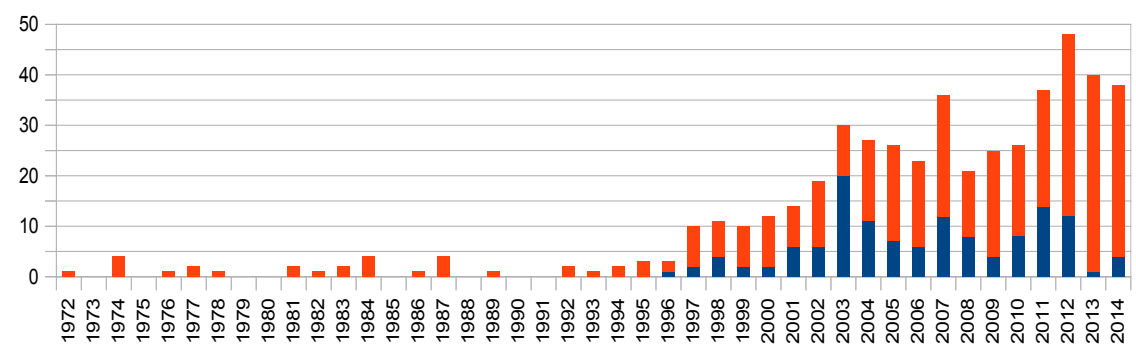

- Estados Sudamericanos Demás miembros del CIADI

Fuente: Elaboración propia en base a datos del CIADI. Actualizado al 31 de enero de 2015.

De acuerdo a datos de la UNCTAD, teniendo en cuenta todos los mecanismos de solución de controversias existentes, al término de 2013 Argentina es el Estado que acumula mayor número de demandas de inversores extranjeros, tanto en Sudamérica como mundialmente, con un total de 53. Es seguido por Venezuela (36), República Checa (27); Egipto (23), Ecuador (22) y Canadá (22) ${ }^{17}$ (UNCTAD, 2014: 8).

\subsection{La década del 2000 en adelante: los cuestionamientos}

En los últimos años, el gran número de demandas recibidas por los Estados de la región ${ }^{18}$, especialmente aquellas basadas en nueva

17 El 57\% de los demandados son países en desarrollo, 27\% desarrollados y 16\% en transición, mientras que el $85 \%$ de los demandantes son nacionales de países desarrollados, $13 \%$ en desarrollo y $2 \%$ en transición, destacándose Estados Unidos (127 casos), seguido por Países Bajos (61), Reino Unido (43), Alemania (39) y Canadá (32). (UNCTAD, 2014: 7 - 9).

18 Tomando únicamente el CIADI, los Estados Sudamericanos fueron demandados en 82 de los 236 casos que se registraron durante el período 2000-2009. Lidera Argentina con 44 demandas en dicho período, de las cuales 37 se derivan de las medidas económicas adoptadas en razón de la crisis económico-social iniciada en diciembre de 2001. 
legislación doméstica relativa a sectores económicos sensibles como ser petróleo, gas y minería, energía eléctrica y otras fuentes de energía, aguas y servicios de saneamiento, finanzas, instrumentos de deuda, entre otros (ver gráficas 5 y 6), que reclaman cuantiosas indemnizaciones ${ }^{19}$, el cuestionamiento de los mecanismos de solución de controversias en sí mismo, así como la ausencia de prueba de la relación directa entre atracción de IED y la vigencia de los $\mathrm{TBI}^{20}$, han generado movimientos en torno a las posiciones de los Estados respecto a la década del noventa.

En este sentido, actualmente los Estados Sudamericanos se han agrupado en tres posiciones: 1) no ratificar TBI ni ser miembro del CIADI (Brasil); 2) denunciar los TBI en vigor y el CW (situación de Bolivia, Ecuador y Venezuela); 3) mantener los TBI en vigor y permanecer en los foros de solución de controversias actuales (Argentina, Chile, Colombia, Guyana, Paraguay, Perú, Surinam y Uruguay).

Gráfica 5: Casos de arbitraje concluidos en el CIADI según sector económico.

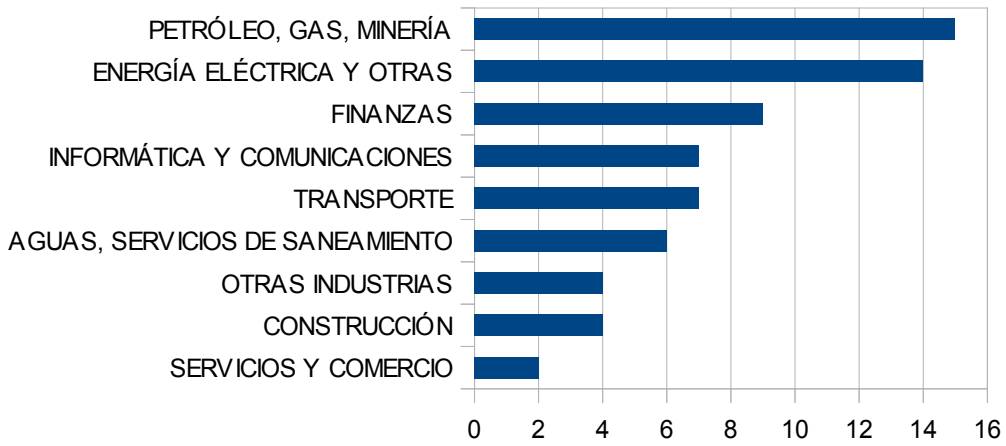

19 A modo de ejemplo, en el Caso Occidental Petroleum contra Ecuador (CIADI caso número $\mathrm{ARB} / 06 / 11$ ), el tribunal arbitral hace lugar a la solicitud de indemnización de casi 1800 millones de dólares. En el caso argentino el monto individual de los reclamos no llega a un cifra como la anterior, por ejemplo en el caso CMS Gas Transmission Company (CIADI caso número $\mathrm{ARB} / 01 / 8)$, directamente relacionado con la crisis económico-social del año 2001, se condena al pago de 133,2 millones de dólares más intereses de los 262 millones de dólares reclamados. No obstante, el acumulado por las demandas presenta otras características. Por ejemplo, en octubre de 2013 Argentina llega a un acuerdo con cinco empresas, una de ellas la mencionada CMS, por el pago de laudos de arbitrajes de inversiones en su contra por 677 millones de dólares, con una quita del 25\% y suscripción de bonos argentinos de por los menos el 10\% (acuerdo transaccional aprobado por la Resolución Nro. 598/2013 del Ministerio de Economía y Finanzas Públicas de Argentina, de fecha 8 de octubre de 2013). Las empresas en cuestión son Azurix (CIADI caso número $\mathrm{ARB} / 01 / 12$ ), $\mathrm{CMS}$ (CIADI caso número $\mathrm{ARB} / 01 / 8)$, Continental Casualty (CIADI caso número ARB/03/9) y Vivendi (CIADI caso número ARB/97/3) y National Grid (arbitraje UNCITRAL).

20 Sobre este punto, Baker señala que los TBI tienen un efecto positivo en la atracción de IED entre 1986 y 1995, pero tal efecto desaparece entre 1996 y 2004. Dados los altos costos de ingresar en un TBI, Baker concluye que sería mejor emplear esos recursos en modernizar los determinantes conocidos de la IED, como ser infraestructura o calidad institucional (Baker, 2012: 24). 
Fuente: Elaboración propia en base a datos del CIADI. Actualizado al 31 de enero de 2015.

Gráfica 6: Casos de arbitraje pendientes en el CIADI según sector económico.

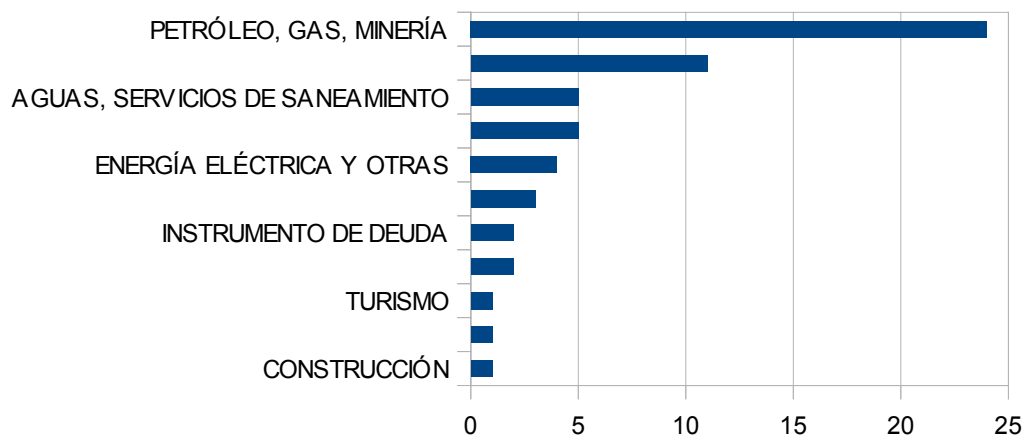

Fuente: Elaboración propia en base a datos del CIADI. Actualizado al 31 de enero de 2015.

\section{LAS TRES POSICIONES EN SUDAMÉRICA}

\subsection{Brasil: ¿tradicional rechazo al sistema o golpe de timón?}

El caso de Brasil es el más significativo en América del Sur. En 1994, con la adhesión al Convenio constitutivo del Organismo Multilateral de Garantía de Inversiones (Seúl, 1985), comienza la práctica de celebración de TBI, firmando $14 \mathrm{TBI}^{21}$, todos entre 1994 y 1999. Si bien seis de estos acuerdo llegan al Congreso Brasilero ${ }^{22}$, no son aprobados y en en marzo de 2002, en el último año del gobierno de Fernando Henrique Cardoso (1995 - 2002), es creado un Grupo de Trabajo Interministerial que determina "la conveniencia de retirar dichos acuerdos del congreso, cuestión que se produjo en diciembre de 2002" (Actis, 2014: 23).

Azevedo (2001: 9) destaca que los inconvenientes para la aprobación de los TBI por parte del Congreso están dados en que comprometen al Estado por períodos muy extensos, privilegian más al inversor extranjero en detrimento del nacional, existen problemas de

21 TBI con Alemania, Bélgica y Luxemburgo, Chile, República De Corea, Cuba, Dinamarca, Finlandia, Francia, Italia, Países Pajos, Portugal, Reino Unido, Suiza y Venezuela.

22 Proyectos de decreto legislativo del año 1996: TBI con Suiza, Portugal y Chile y Reino Unido; y 2000: TBI con Francia y Alemania (Azevedo, 2001: 6) 
constitucionalidad, por ejemplo en relación a la solución de controversias en instancias internacionales de $\operatorname{arbitraje}^{23}$, y la libre transferencia de capitales puede presentar riesgos en la balanza de pagos.

El sistema legal internacional de solución de controversias inversor-Estado, basado en los TBI y el CW, puede ser categorizado como un régimen internacional, en el entendido que se trata de "un conjunto implícito o explícito de principios, normas, reglas y procedimientos de toma de decisión alrededor de los cuales las expectativas de los distintos actores convergen en un área determinada de las relaciones internacionales" (Krasner, 1983: 2) ${ }^{24}$. Los Estados como actores internacionales, forman parte de un régimen siempre que perciban una reciprocidad de intereses o relación ganar-ganar. Por tanto, Brasil representa el caso de un actor que entiende que los beneficios recibidos una vez incorporado en el régimen, no son mayores ni iguales a los que se percibían antes de su incorporación, por tanto elige permanecer fuera.

Sin embargo, esta clara posición de rechazo a los TBI, se ve cuestionada por el hecho que el flujo de inversiones en Brasil ha dejado de ser exclusivamente unidireccional para ser bidireccional, ya que las empresas brasileras han comenzado a realizar inversiones fuera de fronteras, convirtiendo al país en receptor y emisor de IED. En este contexto, en octubre de 2013 Brasil presenta propuestas de TBI a Angola, Nigeria, Mozambique y Sudáfrica (Actis, 2014: 27). El especialista brasilero en Derecho Internacional de las Inversiones, José Augusto Fontoura Costa ${ }^{25}$, explica que los acuerdos propuestos se deben a intereses sectoriales de Brasil en dichos países y a la percepción de fragilidad del marco jurídico en ellos existente ${ }^{26}$.

Con este aparente golpe de timón en la tradicional postura brasilera, cabe preguntarse si el siguiente paso es la adhesión al CW. En este sentido, Fontoura Costa señala que la adhesión "no presenta, per se, ningún potencial nocivo para los intereses nacionales y podría, representar una nueva alternativa para los inversores brasileros en el exterior, especialmente aquellos que se encuentran con marcos regulatorios inestables y riesgo político elevado" (Costa, 2008b).

23 Particularmente colisionan con los siguientes artículos de la Constitución Brasilera (1988): 1.1. "La República Federal del Brasil, formada por la unión indisoluble de los Estados y Municipios y del Distrito Federal, se constituye en Estado Democrático de Derecho y tiene como fundamentos: 1. la soberanía"; y 5.34. "Todos son iguales ante la ley, sin distinción de cualquier naturaliza, garantizándose a los brasileños y a los extranjeros residentes en el País la inviolabilidad del derecho a la vida, a la libertad, a la igualdad, a la seguridad y a la prioridad, en los siguientes términos: (...) 34. la ley no excluirá de la apreciación del Poder Judicial la lesión o la amenaza de derechos."

24 El sistema legal internacional de solución de controversias inversor-Estado, se trata de un régimen condicionalmente abierto, puesto que los Estados que lo conforman aceptan un conjunto de normas establecidas (Bizzozero, 2011: 154).

25 Entrevistado por correo electrónico el 25 de noviembre de 2014.

26 Los textos no son de acceso público, ni se conoce el grado de avance en la negociación. 


\subsection{Bolivia, Ecuador y Venezuela: el abandono del sistema}

Bolivia $^{27}$, Ecuador ${ }^{28}$ y Venezuela ${ }^{29}$ son los primeros Estados en América del Sur abandonar el CIADI, notificando la denuncia al CW el 1 de mayo de 2007, el 2 de julio de 2009 y el 24 de enero de 2012 respectivamente ${ }^{30}$, y comenzando el proceso de denuncia de los TBI en vigor $^{31}$. Este proceso puede enmarcarse en el abandono de un régimen internacional, el sistema legal internacional de solución de controversias inversor-Estado, en el entendido que los costos de permanecer en él son mayores a las alternativas externas.

El caso de Ecuador es de particular interés por los cambios institucionales generados. El proceso de abandono del régimen internacional da inicio en enero de 2008 con la notificación de denuncia de nueve TBI, aquellos en base a los cuales no se habían registrado inversiones recíprocas (Guerra, 2012: 43) ${ }^{32}$. En lo que refiere a los restantes acuerdos, únicamente se llega a la última etapa en el TBI con Finlandia, habiéndose notificado la denuncia a la contraparte el 23 de noviembre de $2010^{33}$. No obstante, debe tenerse en cuenta que en la gran mayoría de los casos, existen cláusulas de ultractividad que determina las disposiciones del TBI se mantienen en vigor por cinco, diez o quince años más, para aquellas inversiones realizadas con anterioridad a la notificación de terminación ${ }^{34}$.

$27 \mathrm{Al}$ inicio del proceso de denuncia, Bolivia cuenta con $21 \mathrm{TBI}$ que la vinculan con: Alemania, Argentina, Austria, Bélgica y Luxemburgo, Chile, China, Corea, Cuba, Dinamarca, Ecuador, Estados Unidos, España, Francia, Italia, Países Bajos, Paraguay, Perú, Reino Unido, Rumania, Suecia, Suiza.

$28 \mathrm{Al}$ inicio del proceso de denuncia, Ecuador tiene 26 TBI que lo vinculan con: Alemania, Argentina, Bolivia, Canadá, Chile, China, Cuba, Estados Unidos, El Salvador, España, Finlandia, Francia, Guatemala, Honduras, Italia, Nicaragua, Países Bajos, Paraguay, Perú, Reino Unido, República Dominicana, Rumania, Suecia, Suiza, Uruguay, Venezuela.

$29 \mathrm{Al}$ inicio del proceso de denuncia, Venezuela tiene $27 \mathrm{TBI}$ que la vinculan con: Alemania, Argentina, Barbados, Bélgica y Luxemburgo, Bielorrusia, Canadá, Chile, Costa Rica, Cuba, Dinamarca, Ecuador, España, Francia, Irán, Italia, Lituania, Países Bajos, Paraguay, Perú, Portugal, Reino Unido, República Checa, Rusia, Suecia, Suiza, Uruguay, Vietnam.

30 De acuerdo al artículo $71 \mathrm{del} \mathrm{CW}$, las denuncias son efectivas seis meses después de su notificación.

31 El Estado que más ha avanzado en el proceso de denuncia de los TBI es Bolivia. Ocho de los acuerdos no son renovados, y en mayo de 2013 se completa el proceso con la denuncia colectiva de los restantes tratados (Orellana López, 2014).

32 TBI con Cuba, El Salvador, Guatemala, Honduras, Nicaragua, Paraguay, República Dominicana, Rumania y Uruguay.

33 El procedimiento tiene los siguientes pasos: 1) Oficio de la Presidencia a la Corte Constitucional solicitando que se pronuncie sobre la denuncia; 2) Dictamen de la Corte Constitucional; 3) Oficio de la Presidencia a la Asamblea Nacional solicitando la denuncia; 4) Informe de la Comisión especializada permanente de soberanía, integración, relaciones internacionales y seguridad integral de la Asamblea Nacional; 5) Resolución del Pleno de la Asamblea Nacional; 6) Notificación escrita de la denuncia a la contraparte en el TBI.

34 Los TBI con Italia y República Dominicana contienen cláusulas de ultractividad por un período de 5 años. En el caso de los TBI con Bolivia, Chile, China, Cuba, Estados Unidos, El Salvador, España, Finlandia, Guatemala, Honduras, Nicaragua, Paraguay, Perú, Rumania, 
En mayo de 2013, Ecuador da un paso más al crear la Comisión para la Auditoría Integral Ciudadana de los Tratados de Protección Recíproca de Inversiones y del Sistema de Arbitraje Internacional en Materia de Inversiones (CAITISA) (Decreto Ejecutivo 1506, 6 de mayo de 2013). La CAITISA está formada por cuatro expertos o investigadores en materia de inversiones y Derecho Internacional, provenientes de la sociedad civil con sus respectivos suplentes, y cuatro representantes del Estado: el Secretario Nacional de Planificación y Desarrollo, la Secretaria Nacional de Gestión de la Política, el Secretario General Jurídico de la Presidencia de la República y el Ministro de Relaciones Exteriores (artículo 6). Sus funciones son analizar los TBI y otros instrumentos internacionales relativos a inversiones que obliguen a Ecuador, así como las normas de arbitraje internacional y los casos contra el Estado (artículo 3).

El especialista en Derecho Internacional Público y miembro de la CAITISA, Javier Echaide ${ }^{35}$, indica que los motivos esgrimidos por Ecuador para denunciar los TBI y el CW se basan en: 1) la incompatibilidad con disposiciones de la Constitución de 2008, principalmente en lo que refiere al establecimiento de una jurisdicción distinta a la doméstica en materia de controversias con inversores extranjeros $\left.{ }^{36}, 2\right)$ la necesidad de dar pasos en relación a la protección de los derechos de la naturaleza, con consagración constitucional por primera vez en la historia de Ecuador ${ }^{37}$; 3) aspectos conyunturales, especialmente las controversias con las empresas Occidental Petroleum (CIADI caso número ARB/06/11) y Chevron (Corte Permanente de Arbitraje); 4) las afectaciones indirectas de los casos que se dirimen en jurisdicciones diferentes y genera problemas al Estado.

En este marco, desde 2009 Ecuador impulsa la creación de una institución regional de solución de controversias en materia de inversiones, el Centro de solución de controversias en materia de inversiones en el ámbito de la UNASUR. Si bien este foro implica realizar

Suiza y Venezuela contienen cláusulas de ultractividad por un período de 10 años. Los TBI con Alemania, Argentina, Canadá, Francia, Países Bajos, Reino Unido y Suecia presentan cláusulas de ultractividad de 15 años. Finalmente, el TBI con Uruguay es la excepción, al no contener cláusulas en este sentido.

35 Entrevista personal realizada el 16 de octubre en Buenos Aires.

36 Artículo 422 de la Constitución de Ecuador (2008): “No se podrá celebrar tratados o instrumentos internacionales en los que el Estado ecuatoriano ceda jurisdicción soberana a instancias de arbitraje internacional, en controversias contractuales o de indole comercial, entre el Estado y personas naturales o jurídicas privadas. Se exceptúan los tratados e instrumentos internacionales que establezcan la solución de controversias entre Estados y ciudadanos en Latinoamérica por instancias arbitrales regionales o por órganos jurisdiccionales de designación de los países signatarios. No podrán intervenir jueces de los Estados que como tales o sus nacionales sean parte de la controversia. En el caso de controversias relacionadas con la deuda externa, el Estado ecuatoriano promoverá soluciones arbitrales en función del origen de la deuda y con sujeción a los principios de transparencia, equidad y justicia internacional."

37 Capítulo séptimo, artículo 71 a 74. 
una prórroga de jurisdicción a su favor, la misma está contemplada dentro de la Constitución ecuatoriana al exceptuarse de la regla general "los tratados e instrumentos internacionales que establezcan la solución de controversias entre Estados y ciudadanos en Latinoamérica por instancias arbitrales regionales o por órganos jurisdiccionales de designación de los países signatarios" (artículo 422) ${ }^{38}$.

\subsection{Los demás Estados Sudamericanos: un grupo heterogéneo}

La tercera posición estáintegrada por el resto delosEstados Sudamericanos, esto es, Argentina, Chile, Colombia, Guyana, Paraguay, Perú, Surinam y Uruguay. Este grupo es heterogéneo, pero en general siguen la tendencia a la firma y entrada en vigor de TBI y adhesión al CW. Al 31 de enero de 2015, Argentina tiene 55 TBI en vigor ${ }^{39}$, Chile $40^{40}$, Colombia $5^{41}$, Guyana $4^{42}$, Paraguay $23^{43}$, Perú $31^{44}$, Surinam $1^{45}$, y Uruguay $29^{46}$.

38 Cabe destacar que Suñé y Vasconcelos señalan que, sin ánimo de duplicar esfuerzos regionales, en el caso de un espacio regional menor como el Mercosur, el ámbito natural para resolver controversias y elaborar normas regionales es el propio Mercosur, y esto debe tenerse en cuenta también en materia de inversiones. Por tanto, proponen que se incluyan las cuestiones relativas a inversiones dentro de la reforma del sistema de solución de controversias mercosuriano (Suñé y de Vasconcelos, 2013: 215 - 217).

39 TBI con Alemania, Argelia, Armenia, Australia, Austria, Bélgica y Luxemburgo, Bolivia, Bulgaria, Canadá, Chile, China, República de Corea, Costa Rica, Croacia, Cuba, Dinamarca, Ecuador, Estados Unidos, Egipto, El Salvador, España, Filipinas, Finlandia, Francia, Guatemala, Hungría, India, Indonesia, Israel, Italia, Jamaica, Lituania, Malasia, Marruecos, México, Nicaragua, Países Bajos, Panamá, Perú, Polonia, Portugal, Reino Unido, República Checa, Rumania, Rusia, Senegal, Sudáfrica, Suecia, Suiza, Tailandia, Túnez, Turquía, Ucrania, Venezuela, y Vietnam. Siguiendo la línea planteada en las gráficas 1 y 2, se incluyen los TBI con Bolivia y Venezuela con distinto grado de avance en los procesos de denuncia.

40 TBI con Alemania, Argentina, Australia, Austria, Bélgica y Luxemburgo, Bolivia, China, República de Corea, Costa Rica, Croacia, Cuba, Dinamarca, Ecuador, El Salvador, España, Filipinas, Finlandia, Francia, Grecia, Guatemala, Honduras, Islandia, Italia, Malasia, Nicaragua, Noruega, Panamá, Paraguay, Perú, Polonia, Portugal, Reino Unido, República Dominicana, República Checa, Rumania, Suecia, Suiza, Ucrania, Uruguay, Venezuela. Siguiendo la línea planteada en las gráficas 1 y 2, se incluyen los TBI con Bolivia, Ecuador y Venezuela con distinto grado de avance en los procesos de denuncia.

41 TBI con China, España, India, Perú, Suiza.

42 TBI con Alemania, China, República de Corea y Reino Unido.

43 TBI con Alemania, Austria, Bélgica y Luxemburgo, Bolivia, Chile, República de Corea, Costa Rica, Cuba, El Salvador, España, Francia, Hungría, Italia, Países Bajos, Perú, Portugal, Reino Unido, República Checa, Rumania, Sudáfrica, Suiza, Taiwán, Venezuela. Siguiendo la línea planteada en las gráficas 1 y 2, se incluyen los TBI con Bolivia y Venezuela con distinto grado de avance en los procesos de denuncia.

44 TBI con Alemania, Argentina, Australia, Bélgica y Luxemburgo, Bolivia, Canadá, Chile, China, Colombia, República de Corea, Cuba, Dinamarca, Ecuador, El Salvador, España, Finlandia, Francia, Italia, Japón, Malasia, Noruega, Países Bajos, Paraguay, Portugal, Reino Unido, República Checa, Rumania, Suecia, Suiza, Tailandia, Venezuela. Siguiendo la línea planteada en las gráficas 1 y 2, se incluyen los TBI con Bolivia y Venezuela con distinto grado de avance en los procesos de denuncia.

45 TBI con Países Bajos.

46 TBI con Alemania, Armenia, Australia, Bélgica y Luxemburgo, Canadá, Chile, China, 
El caso más especial es Suriname, Estado que no sigue la tendencia planteada en el punto 3.1. Si bien firma dos TBI en la década del 90, uno con Indonesia en 1995 y otro con Cuba en 1999, al 31 de enero de 2015, únicamente el TBI con Países Bajos se encuentra en vigor desde 2006, habiendo sido firmado en 2005. A su vez, junto con Brasil son los únicos Estados Sudamericanos que nunca adhirieron al CW.

Otro caso destacable es Argentina puesto que se trata del Estado Sudamericano con mayor número de TBI en vigor. De los 55 acuerdos, celebrados entre 1990 y 2000, 53 corresponden a la presidencia de Carlos Menem (1989 1999). Su celebración es motivada por el proceso privatizador, especialmente de los servicios públicos, la creencia ideológica en las ventajas de una mayor apertura de la economía, la tendencia internacional a la firma de TBI impulsada por el consenso de Washington, y la necesidad de contar con instrumentos jurídicos que brindaran mayor seguridad jurídica a los inversores extranjeros (Beltramino, 2010, 21). Es por este último punto, que la mayoría de los TBI que obligan a Argentina incluyen cláusulas de prórroga de jurisdicción a favor del arbitraje internacional, sin exigir el previo agotamiento de los recursos internos marcando un claro alejamiento de la tradicional doctrina $\mathrm{Calvo}^{47}$.

Sin embargo, son principalmente las empresas concesionarias de servicios públicos ${ }^{48}$, privatizadas en la década del noventa, las que inician procesos arbitrales contra Argentina en base a los TBI celebrados en la misma década ${ }^{49}$, al verse afectadas por las medidas tomadas a partir de diciembre de 2001 para paliar la crisis económico-social. Se destaca la Ley de Emergencia Pública y Reforma del Régimen Cambiario (Ley 25.561 sancionada el 6 de enero de 2002), norma que deja sin efecto las cláusulas de ajuste en dólares u otras monedas extranjeras y las cláusulas basadas en parámetros internacionales, como ser los índices de precios de otros Estados, y "pesifica" los precios y tasas incluidos en contratos públicos (Fernández Alonso, 2013: 58) ${ }^{50}$. En el caso de las controversias dirimidas en el CIADI, al término de 2014 Argentina es demandada en 51 oportunidades $^{51}, 37$ de las cuales están directamente relacionadas

República de Corea, El Salvador, España, Estados Unidos, Finlandia, Francia, Hungría, Israel, Italia, Malasia, México, Países Bajos, Panamá, Polonia, Portugal, Reino Unido, República Checa, Rumania, Suecia, Suiza, Venezuela, Vietnam. Siguiendo la línea planteada en las gráficas 1 y 2, se incluyen los TBI con Bolivia y Venezuela con distinto grado de avance en los procesos de denuncia.

47 Son 43 los TBI que no prevén el agotamiento previo de los recursos internos como condición para el pasaje al arbitraje internacional, 41 firmados durante la presidencia de Menem.

48 Los principales sectores económicos involucrados son: petróleo y gas, energía eléctrica, aguas y saneamiento, informática y comunicaciones (particularmente telefonía).

49 En particular el TBI con Estados Unidos, invocado en 17 de los 37 casos ante el CIADI, directamente relacionados con la crisis económico-social del 2001. En el total de demandas contra Argentina en el Centro (51), este TBI ha sido invocado en 20 oportunidades.

50 En general, las demandas se centran en la ausencia de trato justo y equitativo, trato menos favorable que el otorgado a inversores nacionales y expropiación indirecta, en función de la sanción de las mencionadas normas internas.

51 Al 31 de diciembre de 2014, 29 casos están concluidos y 22 se encuentran pendientes de resolución. 
con la crisis económico-social del $2001^{52}$.

En este contexto, en el año 2003 se produce un cambio estructural en el país una de cuyas premisas es el abandono de la política de negociación y ratificación de TBI. Únicamente se modifica el tratado con Panamá en 2004 y entra en vigor el tratado con Senegal en 2010 que tenía pendiente la ratificación de la nación africana ${ }^{53}$. De acuerdo a Carlos Bianco ${ }^{54}$, Secretario de Relaciones Económicas Internacionales del Ministerio de Relaciones Exteriores y Culto de Argentina, el cambio de modelo parte de una posición ideológica distinta, basada en el desarrollo industrial e inclusión social. Si bien el actual gobierno de Cristina Fernández de Kirchner (2007 - presente) es muy crítico de los resultados generados por los TBI y se ha discutido internamente la posibilidad de denuncia, no se ha avanzado en esta dirección. Por tanto, se continúa renovando automáticamente los TBI en vigor y se mantiene la membresía al CIADI.

Siguiendo la teoría de los regímenes internacionales, si bien Argentina se mantiene dentro del régimen, lo hace con restricciones que no implican el abandono del mismo. No obstante, en la Cámara de Diputados se han presentado diversos proyectos que sí proponen el abandono del régimen, ya sea mediante la denuncia del CW o los TBI en vigor o la declaración de nulidad absoluta de las mencionadas normas ${ }^{55}$. En el primer caso, el fundamento está dado en dos aspectos: 1) las características de las cláusulas habitualmente incluidas en los TBI, en especial la CNMF, la cláusula de estabilidad y la cláusula paraguas ${ }^{56}$, y 2) la renuncia de soberanía relativa a la jurisdicción territorial de los tribunales nacionales, a favor del CIADI u otros tribunales arbitrales internacionales ${ }^{57}$. En el segundo caso, siguiendo a Costante (2012) se explica que, dado que los TBI tienen rango supralegal pero

52 El año 2003 es el de mayor registro de casos contra Argentina: 17 de los 20 registrados contra Estados Sudamericanos, y de los 30 registrados en total.

$53 \mathrm{El}$ acuerdo es firmado en 1993 y ratificado por Argentina en 1994.

54 Entrevista personal realizada el 22 de octubre de 2014 en Buenos Aires.

55 En el primer grupo se encuentran, por ejemplo, los proyectos con número de trámite parlamentario 8 de 14 de marzo de 2011, 37 de 25 de abril de 2006, 3 de 3 de marzo de 2006, 52 de 13 de mayo de 2000, mientras que en el segundo grupo se incluye, por ejemplo, el proyecto con número de trámite parlamentario 182 de 14 de diciembre de 2012. Los proyectos llevan la firma de diputados de los siguientes partidos políticos: Movimiento Proyecto Sur, Partido Socialista, Soberanía Popular, Emancipación y Justicia, Concertación Entrerriana, Sí por la Unidad Popular, GEN, y/o ARI, según el caso.

56 Es especialmente interesante el caso de la CNMF, dado que el TBI con Panamá prevé que "ninguna de las Partes Contratantes tomará directa o indirectamente medidas de expropiación o de nacionalización, ni ninguna otra medida similar" (artículo 3). Por efecto de la mencionada cláusula, esta disposición sería aplicable a todos los TBI que Argentina tiene en vigor.

57 En los 55 TBI en vigor que fueron analizados, los mecanismos de solución de controversias previstos son: el CIADI (51 TBI), tribunales arbitrales ad hoc según el Reglamento de Arbitraje de la UNCITRAL(49), la jurisdicción doméstica (45), el mecanismo complementario del CIADI (42), otros (5). 
infraconstitucional ${ }^{58}$, son absolutamente nulos al colisionar con las disposiciones constitucionales que prevén la jurisdicción de los tribunales locales en todos los asuntos previstos en la Constitución Argentina (1994), como ser contraer empréstitos sobre el crédito de la Nación y arreglar el pago de la deuda interior y exterior de la Nación (artículos 75 incisos 4 y $7^{59}, 116^{60}$ y $117^{61}$ ).

\section{CONCLUSIONES: REALIDADES Y PERSPECTIVAS}

Actualmente, en los Estados Sudamericanos se perciben rasgos de transformación en lo que refiere al sistema legal internacional de solución de controversias inversor-Estado. Sin embargo, existe fragmentación en las estrategias seguidas por los Estados, ya sea en relación a los TBI y el CW: permanecer en el sistema, no ser parte de él, o abandonarlo. La ausencia de una voz común lleva a que las políticas individuales, si bien en apariencia sólidas a nivel nacional, colisionan en el contexto regional.

El proyecto ecuatoriano de creación de un Centro de solución de controversias en materia de inversiones de UNASUR ${ }^{62}$, es un paso para neutralizar la fragmentación de estrategias a nivel regional y procurar la construcción de un sistema legal de solución de controversias inversor-Estado como régimen internacional propio, basado en lógicas regionales. Dado que la UNASUR es un proceso intergubernamental, que no implica la cesión de soberanía, y que en el proyecto los Estados estarán facultados a solicitar el agotamiento previo de los recursos internos (Fiezzoni, 2011: 7) ${ }^{63}$, es posible afirmar que se perfila un leve

58 De acuerdo al artículo 74 inciso 22 de la Constitución Argentina (1994), los tratados tienen rango supralegal pero infraconstitucional, salvo aquellos enumerados a texto expreso a los que se les otorga jerarquía constitucional. Estos son: la Declaración Americana de los Derechos y Deberes del Hombre; la Declaración Universal de Derechos Humanos; la Convención Americana sobre Derechos Humanos; el Pacto Internacional de Derechos Económicos, Sociales y Culturales; el Pacto Internacional de Derechos Civiles y Políticos y su Protocolo Facultativo; la Convención sobre la Prevención y la Sanción del Delito de Genocidio; la Convención Internacional sobre la Eliminación de todas las Formas de Discriminación Racial; la Convención sobre la Eliminación de todas las Formas de Discriminación contra la Mujer; la Convención contra la Tortura y otros Tratos o Penas Crueles, Inhumanos o Degradantes; la Convención sobre los Derechos del Niño; Convención Interamericana sobre Desaparición Forzada de Personas; Convención sobre imprescriptibilidad de los crímenes de guerra y de los crímenes de lesa humanidad.

59 Artículo 75. "Corresponde al Congreso: 4. Contraer empréstitos sobre el crédito de la Nación. (...); 7. Arreglar el pago de la deuda interior y exterior de la Nación”.

60 Artículo 116. "Corresponde a la Corte Suprema y a los tribunales inferiores de la Nación, el conocimiento y decisión de todas las causas que versen sobre puntos regidos por la Constitución (....)". 61 Artículo 117. "En estos casos la Corte Suprema ejercerá su jurisdicción por apelación según las reglas y excepciones que prescriba el Congreso (....).

62 Luego de cuatro años de trabajo, el Grupo de Trabajo de Expertos de Alto Nivel, concluyó el texto del acuerdo constitutivo en noviembre de 2014, el cual debe ser sometido a ratificación por los doce miembros de la UNASUR, según información de la Cancillería Ecuatoriana, disponible en: <http://www.cancilleria.gob.ec/expertosdeunasurconsolidantextoparalacreacion delcentrodesoluciondecontroversiasenmateriadeinversiones/> [consultado 02.02.15].

$63 \mathrm{Si}$ bien no es un regreso completo a la doctrina Calvo, se percibe un claro respeto a la soberanía estatal al darle al Estado la posibilidad de elección. 
retorno a la soberanía estatal en la solución de controversias en materia de inversiones.

No obstante, sería deseable que este proceso de construcción de un sistema legal regional interpele a los Estados Sudamericanos a discutir públicamente sobre otros aspectos vinculados con los TBI, como ser la CNMF, las cláusulas de ultractividad, el trato justo y equitativo, el concepto de expropiación indirecta, el agotamiento previo de los recursos internos, y el concepto de inversión en sí mismo, entre otros. De esta forma se contarían con bases sólidas para la negociación de futuros acuerdos o la renegociación de los vigentes contemplando los intereses de la región, particularmente el modelo de desarrollo al que se quiera apostar.

\section{REFERENCIAS BIBLIOGRÁFICAS}

ACTIS, Esteban. "Brasil y la promoción de Tratados Bilaterales de Inversión: El fin de la disyuntiva". Latin American Journal of International Affairs [en línea]. 2014, vol 6, $\mathrm{n}^{\circ}$ 1, p. 18-33 [consultado 19.11.14]. Disponible en: <http://www.lajia.net/volumenes/LAJIA\%20vol6\%20 n1\%20Art02.pdf?attredirects $=0 \& d=1>$.

ARBUET VIGNALI, Heber. ¿Quién prima? El lastre de una teoría heredada, sobre un problema real del derecho en la posmodernidad. Estudio del Consejo Uruguayo para las Relaciones Internacionales [en línea] 2013 [consultado 30.08.14]. Disponible en: <http://curi.org.uy/ archivos/estudiocuri08del13arbuet.pdf $>$.

AZEVEDO, Déborah Bithiah de. Os acordos para a promoção e a proteção recíproca de investimentos assinados pelo Brasil [en línea]. Brasília: Câmara dos Deputados, 2001 [consultado 31.05.14]. Disponible en: <http://www2.camara.leg.br/documentos-e-pesquisa/publicacoes/ estnottec/tema3/pdf/102080.pdf $>$.

BAKER, Paul (2012). Who Enters Into Bilateral Investment Treaties and Do They Have an Impact on Foreign Direct Investment? [en línea]. 2012 [consultado 23.01.15]. Disponible en: <https://editorialexpress. com/cgi-bin/conference/download.cgi?db_name=SAEe2012_Job_ Market\&paper_id=49>.

BANIFATEMI, Yas. "The emerging gurisprudence on the Most-FavoredNation Treatment in investment arbitration". En: BJORKLUND, Andrea; et.al. (edit). Investment Treaty Law. Current Issues III - Remedies in International Investment Law: Emerging Jurisprudence of International Investment Law. Londres: BIICL, 2009. p. 241-273.

BELTRAMINO, Ricardo. Promoción de inversiones en los acuerdos de inversiones firmados por Argentina. Documento de trabajo Nro. 49, Mayo 2010. Área de Relaciones Internacionales. Buenos Aires: FLACSO, 2010 [consultado 24.05.14]. Disponible en: <http://rrii.flacso.org.ar/ wp-content/uploads/2010/06/FLA_Doc49.pdf>. 
BIZZOZERO, Lincoln. Aproximación a las relacionales internacionales. Una mirada desde el siglo XXI. Montevideo: Ediciones Cruz del Sur, 2011. BOEGLIN, Nicolás. Ecuador y el CIADI: nuevo pulso con posibles repercusiones. América Latina en Movimiento, publicado el 10 de octubre de 2012 [en línea]. 2012 [consultado 23.01.15]. Disponible en: <http:// alainet.org/active/58693>.

BOHOSLAVSKY, Juan Pablo. Tratados de protección de las inversiones e implicaciones para la formulación de políticas públicas (especial referencia a los servicios de agua potable y saneamiento). Santiago de Chile: Naciones Unidas, 2010. (Colección Documentos de proyecto, $\mathrm{n}^{\circ}$. 326).

BURGOS-DE LA OSSA, María Angélica y LOZADA-PIMIENTO, Nicolás. "La protección diplomática en el marco de las controversias internacionales de inversión". International Law, Revista Colombiana de Derecho Internacional [en línea]. 2009, $\mathrm{n}^{\circ} 15, \mathrm{p} .243-278$ [consultado 10.09.14]. Disponible en: <http://www.scielo.org.co/pdf/ilrdi/n15/n15a09.pdf > .

CARRAU, Natalia y VALDOMIR, Sebastián. La incidencia de los Tratados de Protección de Inversiones en el Mercosur. Montevideo: CEFIR, GIZ, 2012. (Documento de trabajo 013).

COSTA, José Augusto Fontoura. "Direito Internacional do Investimento Estrangeiro" [Tesis]. Universidade de São Paulo. São Paulo, 2008.

COSTA, José Augusto Fontoura. "Investidores brasileiros e arbitragem internacional". Puentes [en línea]. 2008, vol 4, n ${ }^{\circ} 6$ [consultado 13.11.14]. Disponible en: <http://www.ictsd.org/bridges-news/pontes/ news/investidores-brasileiros-e-arbitragem-internacional>.

COSTANTE, Liliana. Soberanía nacional vs. CIADI: ¿Estados o mercados? Revista de Derecho Público [en línea]. 2012, año $I, n^{\circ} 2$, p. 59-105 [consultado 16.05.13]. Disponible en: <http://www.infojus.gov. ar/_pdf_revistas/DERECHO_PUBLICO_A1_N2.pdf >.

FACH GOMEZ, Katia. Latin America and ICSID: David versus Goliath? [en línea]. 2010 [consultado 14.12.14]. Disponible en: <http://ssrn.com/ abstract $=1708325>$.

FERNANDEZ ALONSO, José. "Controvérsias entre Estados e investidores transnacionais: reflexoes sobre o acúmulo de casos contra a República Argentina". Revista Tempo do mundo [en línea]. 2013, vol 5, nº 1, p. 45-87 [consultado 12.11.14]. Disponible en: <http://www.ipea.gov.br/portal/ images/stories/PDFs/rtm/140903_rtmv5_n1_port_cap2.pdf $>$.

FIEZZONI, Silvia."Las Principales Características de la Propuesta de Ecuador". Investment Treaty News [en línea]. 2011, tomo 2, $\mathrm{n}^{\circ} 2,2$, Diciembre 2011/Enero 2012, p. 6-7 [consultado 14.12.14]. Disponible en: <http://www.iisd.org/pdf/2012/iisd_itn_january_2012_es.pdf $>$.

GUERRA, Gustavo. "Las disposiciones legales que desarrollan los preceptos constituciones sobre la inversión privada extranjera en el Ecuador". Foro: Revista de Derecho, 2012, n 17, p. 31-62.

HERZ, Mariana. "Régimen argentino de promoción y protección de 
inversiones en los albores del nuevo milenio: de los tratados bilaterales, Mercosur mediante, al Alca y la OMC". Revista Electrónica de Estudios Internacionales [en línea]. 2003, $\mathrm{n}^{\circ} 7$ [consultado 16.05.13]. Disponible en: $<$ http://www.reei.org/index.php/revista/num7/archivos/M.Herz(reei7).pdf>. KRASNER, Stephen. "Structural causes and regime consequences: regimes as intervening variables". En: KRASNER, Stephen (ed). International regimes. Ithaca: Cornell University Press, 1983.

ORELLANA LOPEZ, Aldo. Bolivia denuncia sus tratados bilaterales de inversión e intenta poner fin al poder de las corporaciones para demandar al país en Tribunales Internacionales [en línea]. Red por la Justicia Social en la Inversión Global, 2014 [consultado 14.12.14]. Disponible en: <http:// justinvestment.org/wp-content/uploads/2014/07/Bolivia-denunciasus-Tratados-Bilaterales-de-Inversi $\% \mathrm{C} 3 \% \mathrm{~B} 3 n$-e-intenta-poner-fin-alpoder-de-las-corporaciones-para-demandar-al-pa\%C3\%ADs-en-Tribunales-Internacionales1.pdf $>$.

SALACUSE, Jeswald The Law of Investment Treaties. Oxford: Oxford University Press, 2010.

SCHREUER, Christoph. The ICSID Convention: A Commentary, Second Edition. Cambridge: Cambridge University Press, 2009.

SUÑÉ, Natasha y VASCONCELOS, Raphael Carvalho de. "Inversiones y solución de controversias en el Mercosur". Revista de la Secretaría del Tribunal Permanente de Revisión [en línea]. 2013, año 1, nº 2, p. 195220 [consultado 23.01.15]. DOI: <http://dx.doi.org/10.16890/rstpr. a1.n2.195>.

TAMBURINI, Francesco. "Historia y Destino de la Doctrina Calvo: ¿Actualidad u obsolescencia del pensamiento de Carlos Calvo?" Revista de estudios histórico-jurídicos [en línea]. 2002, n XXIV, p. 81-101 [consultado 23.01.15]. Disponible en: <http://www.rehj.cl/index.php/ rehj/article/view/363/343>.

TORREJA MATEU, Helena (2012). "Protección diplomática”. En: SÁNCHEZ, Víctor (ed). Derecho Internacional Público. Barcelona: Huygens Editorial, 2012, p. 315-330.

UNCTAD. International Investment Agreements Issues Note: Recent Developments in Investor-State Dispute Settlement [en línea]. Ginebra, 2014. Nro. 1, Abril 2014 [consultado 20.06.14]. Disponible en: $<$ http://unctad.org/en/PublicationsLibrary/ webdiaepcb2014d3_en.pdf $>$.

UNCTAD (2010). International Investment Agreements Issues Note: Denunciation of the ICSID convention and BITS: impact on investor-state claims. Nro. 2,. Ginebra, 2010 [consultado 16.07.14]. Disponible en: <http://unctad.org/en/Docs/ webdiaeia20106_en.pdf>. 